\title{
THE PHILOSOPHY OF PARADIGM SHIFT ACROSS THE HISTORY OF ARCHITECTURAL PRACTICES
}

\author{
M.T.Saleh ${ }^{1}$, Y. Mansour ${ }^{2}$, S. Kamel $^{3}$, K. Dewidar ${ }^{4}$ AND A.A.Farid ${ }^{5}$
}

\begin{abstract}
Today, many attempts and efforts are made to articulate the contemporary architectural practices in the early $21^{\text {st }}$ century, where some contributions deal with the functionality and the performativity of the architectural buildings with respect to measurable parameters like optimization of consumption and efficiency, while others try to link the current practices with their historical traditional one. Some discussions are about parametricism and others about technology and IOT. These debates deal with architecture as a discipline of isolated islands where each stands alone and initiate in a new horizon that was never existed before. The research investigates the possible patterns of transitions of architectural paradigms which interrelates the current practices to their original paradigms, exploring the critical nature of evolutionary and revolutionary changes of architectural paradigms. This aims to introduce a novel approach in investigating and criticizing the practice of architecture with respect to its foundations and influencing parameters like beliefs, values and goals. Furthermore, interpretations to the philosophy of paradigm shift, a theory of drivers of paradigm changes, and the possible paradigms interplay is concluded to improve the understanding of the current paradigms of architectural practices.
\end{abstract}

KEYWORDS: Architectural practices, Transitions of architectural paradigms, Evolutionary changes, Revolutionary changes, Philosophy of paradigm shift, Drivers of paradigm changes.

\footnotetext{
1 Ph.D. Candidate, Assistant lecturer, Department of Architecture, Faculty of Engineering, Ain Shams University, Egypt, Eng_Mennatarek@yahoo.com

2 Professor, Department of Architecture, Faculty of Engineering, Ain Shams University, Egypt

3 Professor, Department of Architecture, Faculty of Engineering, Ain Shams University, Egypt

4 Professor, Department of Architecture, Faculty of Engineering, BUE, Egypt

5 Associate Professor, Department of Architecture, Faculty of Engineering, Ain Shams University, Egypt
} 


\section{INTRODUCTION}

The discipline of architecture was first investigated by the 18th century seen as a craft industry, just like Vitruvius describing architecture as a natural phenomenon, understanding architecture as its physical objects "erected buildings". As we know today architecture shifted from its standing monuments to its ideal objects to the thoughts and knowledge of architects ${ }^{1}$. Later architecture became a product of the mind, at this point architectural practices have been linked to the intellectual waves and paradigms that reshaped the humanity in the different eras ${ }^{2}$.

However, architectural paradigms have been discussed through various perspectives, where each has a new different scope upon which facts, illustrations and analysis are dependent. Throughout all the critical writings and documentations on the field of architecture, it's obvious that the architecture initially described relative to the parent civilization. Then, architecture resulted from conceptual philosophies and producing prototypes that carry the influences of the ideologies of its age. By the end of the twentieth century writings about architecture of Pioneers appeared to spread all over the architectural community reflecting architecture practice with specified techniques and intentions based upon professional practice with terminologies like "starchitects" why the discussion of the nature of architecture changed nowadays? what kind of transitions happened and not yet understood in the architectural practices?

Architectural paradigms are the intellectual models and frameworks of actions of architects and practitioners with their beliefs, values and merits towards their actions, responses and practices ${ }^{4}$. Each paradigm starts in a primitive form that by time and effort evolve to reach its peak towards perfectionism, while in other times a paradigm shift occurs that takes the whole discipline to a new island of practice or paradigm due to changes primitively seen as changes in meanings or technologies ${ }^{5}$. These definitions need more contributions and interpretations to understand the critical philosophy of paradigm shift, which by its turn will lead the architectural community to better understanding of the current practices with its qualities and shared fundamentals with its proceeding paradigms and socio-cultural contexts.

\footnotetext{
${ }^{1}$ Tahl Kaminer, Architecture, Crisis and Resuscitation: The Reproduction of Post-Fordism in LateTwentieth-Century Architecture, Architecture, Crisis and Resuscitation: The Reproduction of Post-Fordism in Late-Twentieth-Century Architecture, $2011<\mathrm{https}$ ://doi.org/10.4324/9780203831847>.

${ }^{2}$ Charles Jencks, "'The Architecture of Jumping Universe ", Academy Edition, Great Briton, 1997.

${ }^{3}$ Charles Jencks.

${ }^{4}$ J BERMUDEZ, 'On Paradigms \& Avant Garde: Peeking into the Architectural Mind', Design Methods, 30.3 (1996), 1-19 <http://www.arch.utah.edu/people/faculty/julio/parad.htm>.

5 Donald A. Norman and Roberto Verganti, 'Incremental and Radical Innovation: Design Research vs. Technology and Meaning Change', Design Issues, $30.1 \quad$ (2014), 79-85 <https://doi.org/10.1162/DESI_a_00250>.
} 
This research is a qualitative study to introduce a novel approach linking the current architectural paradigms to their origins and foundations, bridging the gap between the isolated islands and their emitters across the history of architecture, as it is believed that innovation always has an initial-common floor with its history, which represents the traditional foundation of the new ideas and creativity. New architectural paradigms are believed to link with their past at some point from where they later split and deprived. These transitions have been recognized and identified through the analysis of several shifts of architectural paradigms across history.

From here, the research extracts the drivers of paradigm changes and their different operational models. Besides, introducing three possible types of radicalrevolutionary changes that aids in understanding the philosophy of paradigm shifts across the paradigms of architectural practices with regard to the paradigm's beliefs, philosophies, values and goals. These findings offer a time-less philosophical platform for criticizing the architectural practices at any context.

\section{The Meaning of a Paradigm}

The Word "Paradigm" first appeared in the late $15^{\text {th }}$ century, from the Greek word "Paradigma" which means "Pattern", In English Cambridge Dictionary Paradigm means "A model of something, or a very clear and typical example of something". Also, it is defined in the scientific dictionary as "a philosophical and theoretical framework of a scientific school or discipline within which theories, laws, and generalizations and the experiments performed in support of them are formulated". 2 In disciplines of sociology paradigms are "The fundamental models or frames of reference we use to organize our observations and reasoning", , While in philosophy a paradigm relates to the pattern of intellectual activities of the community practitioners.

Accordingly, a paradigm can be seen as the manner of acting between the community members within a defined hypothetical boundaries, a model of the vital active responses and actions of the different civilizations across time towards uprising phenomenon and anomalies.

Thus, architectural paradigms can represent how architects deal with their acquired knowledge and available tools towards their goals and values, carrying their philosophies reflected on the morphology of the erected buildings. An architectural paradigm may represent a shared framework of action that engages practitioners with the same beliefs, values and philosophy in a certain age through

\footnotetext{
1 'Https://Dictionary.Cambridge.Org/Dictionary/English/Paradigm'.

2 'Https://Www.Merriam-Webster.Com/Dictionary/Paradigm'.

${ }^{3}$ Dorothy Giles Williams and Earl R. Babbie, 'The Practice of Social Research.', Contemporary Sociology, 5.2 (1976), $163<$ https://doi.org/10.2307/2062956>.
} 
autonomous creativity that leads the architectural practices to certain style or school with common visual characteristics that is distinguished from others along history. These paradigms are critically related to their cultural contexts; web of conditions and influences that is seen as drivers of the architectural paradigms with their physical products or "Idioms".

\section{The Progress and Transitions of Paradigms}

The traditional development of the body of knowledge shows the process of addition of new truths to the foundation of old truths as an accumulation progress. This ideology of linearity expresses any addition to be on the same route of ideas, beliefs and values within a context of a common paradigm "A Uni-Shared Model".

However, Thomas Kuhn ${ }^{1}$ challenged this philosophy inducing the theory of "Paradigm shift"; describing a new type of development through a process in which an accepted paradigm is unable to account for accumulating anomalies by the available knowledge or the traditional practice among the society in the previous time. Therefore, Community practitioners engage in extraordinary research to deal with these anomalies, with their new beliefs and goals through constructing new theories and advanced science clouds. This calls for a new paradigm serving the contemporary needs and problems, which announces a transition from the old accepted practice towards new concepts, procedures, standards and realities that is a way similar to a "religious conversion"2. These are known as "Paradigms of Revolutions" that split besides the previously known "Paradigms of Evolutions" (Figure 1).

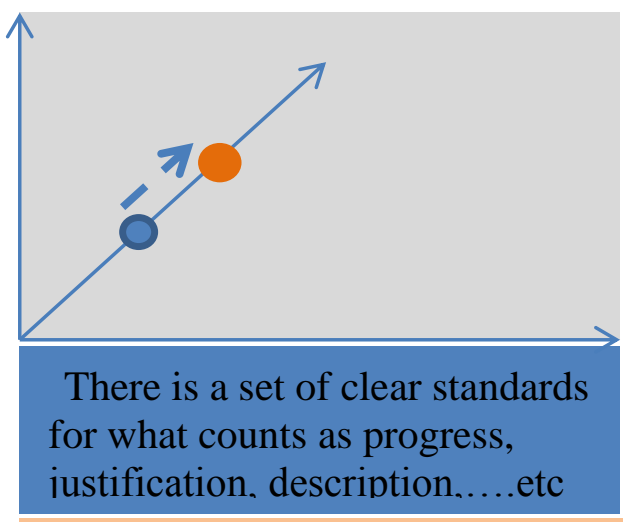

Evolutions within a paradigm

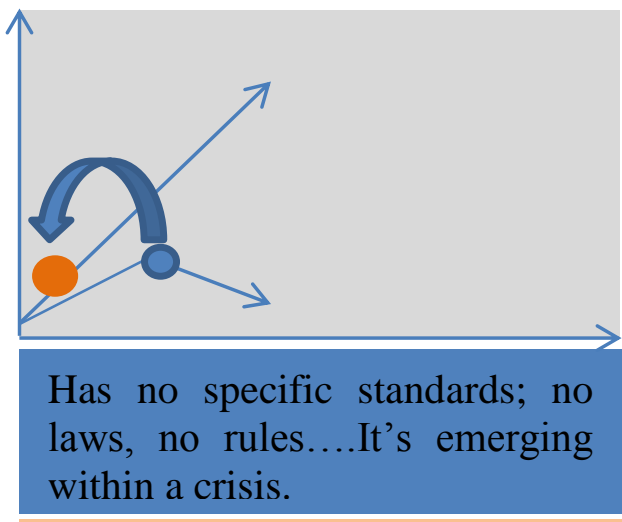

A paradigm shift

Figure 1: The two types of Transitions in the philosophy of paradigm progress

1 Thomas Samuel Kuhn was an American philosopher of science, whose 1962 book "The Structure of Scientific Revolutions" was influential in both academic and popular circles, introducing the term paradigm shift, which has since become an English-language idiom.

${ }^{2}$ John Hassard, Sociology and Organization Theory,Positivism, Paradigms and Postmodernity, עלון הנוטע (Cambridge University Press, 1993), LXVI.P.89. 


\section{The Hill-ClimbingTransitional Model of Architectural Paradigms}

Hill-climbing paradigm is a model that identifies two patterns of transitional-changes between paradigms of innovation (Figure:2), which embraces architectural paradigms ${ }^{1}$,

- Incremental changes "Evolutionary Changes": (From A-B), where transitions are intended towards the peak of the same hill, seeking efficiency, quality and adaptation within boundaries of the existing paradigm

- Radical changes "Revolutionary Changes": (From B-C) where drastic transitions are unintended from one hill to another, due to changes in meanings or technology that moves the practice out of the existing boundaries to a new paradigm with higher potentials and innovative methodologies (Point D).

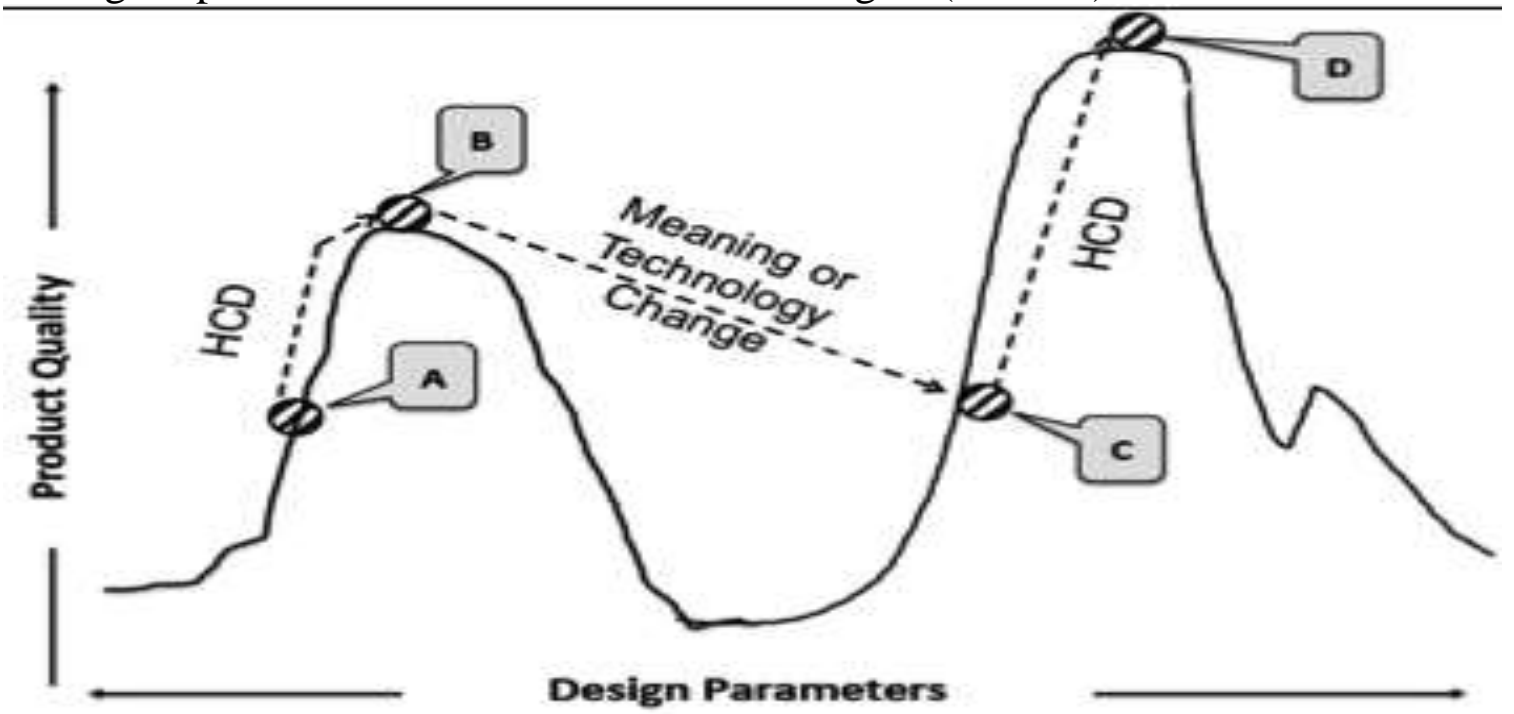

Figure 2: The Hill-Climbing Paradigm of Evolutionary and Revolutionary Changes

\subsection{The Evolutionary Changes of Architectural Paradigms}

The evolutionary changes of a paradigm is the normal activity of practitioners to complete their journey exploring the world around them in their form of reality, it folds the same meanings, value system, ideologies, realities, standards and procedures. "Stability and consistency" are conceptual foundations that orient the evolutionary changes in any community ${ }^{2}$, which leads to flourishing results in the efforts for development. Evolutionary changes probably seek quality as well as quantity relative to the initial product, aid in providing answers, offering solutions

\footnotetext{
${ }^{1}$ Norman and Verganti.

2 Thomas S. Kuhn, The Structure of Scientific Revolutions, The Structure of Scientific Revolutions (University of Chicago Press, 1970) <https://doi.org/10.7208/chicago/9780226458106.001.0001>.
} 
to the rising conflicts and ongoing changes, and enhancing the properties of the existing within a standard rationality. Thus, evolutionary changes can be deduced as a kind of motion within a stable context of realness, a process that is planned and intended as a priority for the community to work on and develop in its way of perfection.

Previous exemplars are sometimes the references of the current practice towards progress, it is a belief from the practitioners with the success of the existing exemplar "paradigm", and the efficiency of the foundations on which it is built, here evolutionary changes are closer to Kuhn's methodological approach "Concrete puzzle-solving" which we described above as "motion within stable context". The keys of evolutionary changes may appear as: accumulative knowledge, depth of investigations, and continuous endeavors.

Like the reflections of the evolution of iron industry on architecture; where the continual developed properties of cast iron, steel structures, the steel skeleton system, and the steel frames influenced the architectural construction and structure evolved prototypes, where the implications of the new industries were reflected on the Metal bridge designs in the beginning, domes, iron plates, facades, till reaching the new high-rise building prototypes of Chicago School of architecture (Figure:3), where the building models were accordingly developed from being of timber, stone, concrete and the traditional preexisted construction materials to steel and glass frames of skyscrapers that was an evolution in the architectural product ${ }^{1}$
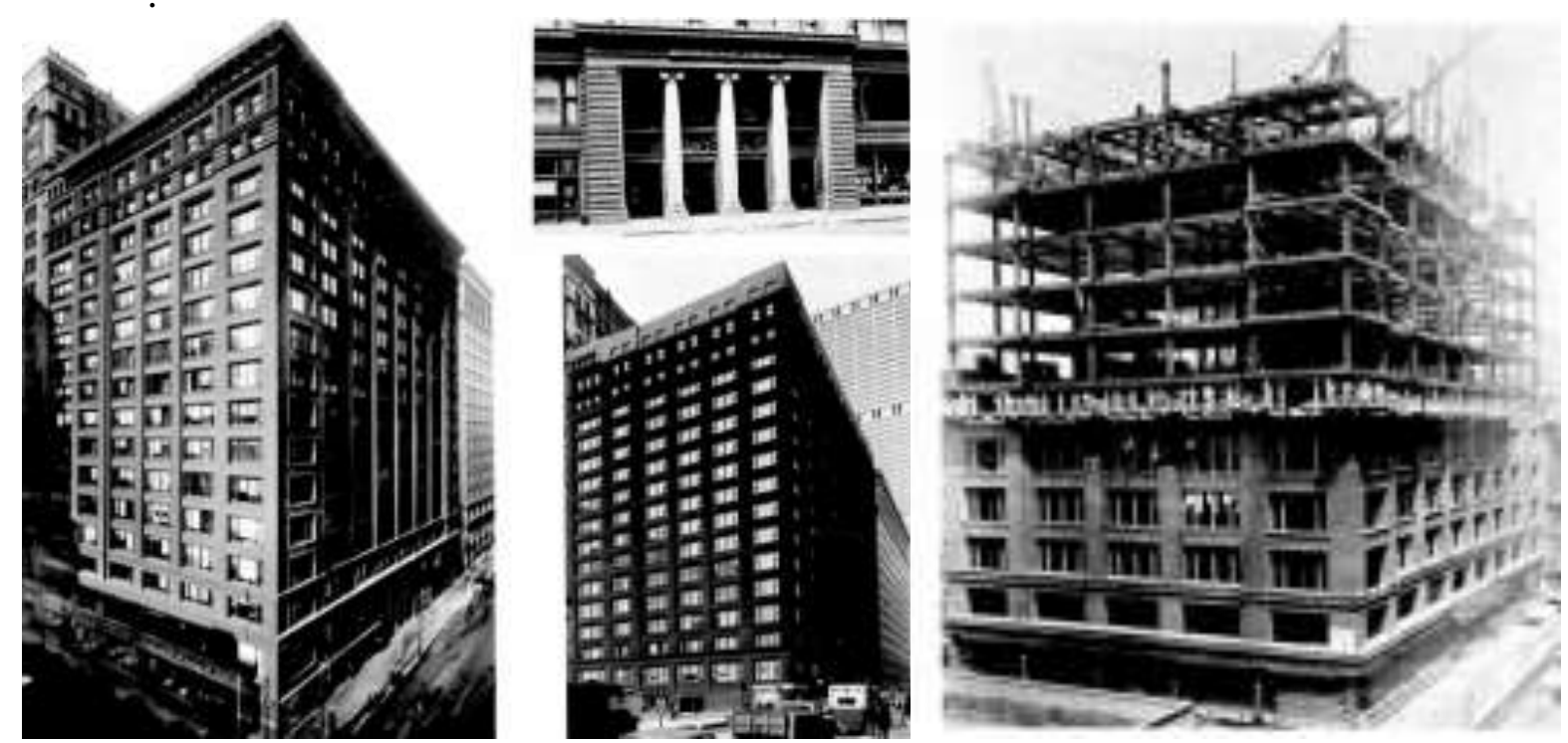

Figure 3: A High-rise building Model of Chicago School of Architecture

\footnotetext{
${ }^{1}$ Ya-Guang SUN, 'Wind-Bracing Systems and the Materials of Chicago School (Architecture) at the End of 19th Century', DEStech Transactions on Engineering and Technology Research, mdm, 2017 <https://doi.org/10.12783/dtetr/mdm2016/4939>.
} 


\subsection{The Revolutionary Changes of Architectural Paradigms}

Revolutionary changes of paradigms are those developments that pursue the emergence of new influential drivers shifting the normal activity of social actors in these paradigms to what is known as "revolutionary activity"; as a result of radical changing forces that pops-up like new discoveries, or from the changing social structure holding internal conflicts and contradictions ${ }^{2}$. Both can be considered as provoking problems or questions that rises inquiry of new solutions of originality.

New approaches and realities are constructed on these drastically different changes, a revolutionary action of transitioning from the common paradigm to a new paradigm is clearly observed. No concepts of stability or absolutism or everlasting truths are folded within revolutionary changes; the world espouse new meanings, methods, goals and objectives that is inconsistent with the old paradigm. Kuhn described "Rather than being an interpreter, the scientist who embraces a new paradigm is like the man wearing inverting glasses"3. This seems to fold a clear relativist approach in interpreting the pattern of practice in any; where the accepted reality and belief are not merely the best fitting, but the best accepted or propaganged called "Leap of faith" .

These radical changes substitute the world that was previously known introducing new ideologies and philosophies that may reformulate the culture of the whole world through "community conversion experience". Maybe we can mention how the world changed after the most critical changes in the history like the Revolutionary Change from the Fordism to Post-Fordism society:

As by the end of the world war era, gains of capitalism were raised besides the projects of developments in the Capitalist countries "Fordism society". In $20^{\text {th }}$ Century Friedrich Hayek thoughts predicted a free market state as a result of collective fragments of knowledge ${ }^{6}$. This new approach emphasises market relations, and re-tasking the role of the state and individual responsibility". It encourages deregulation of markets, the corporatization of public services, and the privatization of public assets ${ }^{7}$. When rich countries moved away from a regulated economy of mass production and mass consumption, organized within nation states, David Harvey's writings in 1990 saw it replaced with "Post-Fordism society" that is an economy built on just-in-time production, the internationalization of capital, the

\footnotetext{
${ }^{1}$ Kuhn.

${ }^{2}$ Van der Berge, 'Dialectics and Functionalism: Toward a Theoretical Synthesis', American Sociological Review, 28.5 (1963), 695-705.

${ }^{3}$ Kuhn.

${ }^{4}$ Thomas Kuhn S, 'Review Articles', 1971, 287-97.P.8

${ }^{5}$ Ibid,P.10

${ }^{6}$ Stephen Metcalf, 'Neoliberalism: The Idea That Swallowed the World', The Guardian, 2017.

7 Jamie Peck, Nik Theodore, and Neil Brenner, 'Neoliberal Urbanism Redux?', International Journal of Urban and Regional Research, 37.3 (2013) <https://doi.org/10.1111/1468-2427.12066>. 
deregulation of industry, insecure labor and the entrepreneurial self. The new reinterpretations of meanings in the social structure dynamics are the drivers of this radical change, traditional ideologies have changed, goals and approach all have suffered great transformation that lead to "A Paradigm Shift". The ideological shift in this paradigm was the evolve of the third way democracy that was coherent to the neoliberal approach or the Post-Fordism society (Table:1), that is characterized by several changes in social structure like ${ }^{123}$ :

\begin{tabular}{|l|l|}
\hline \multicolumn{2}{|c|}{ The Radical Changes in The Cultural Contexts } \\
\hline Capitalism (Fordism Society) & $\begin{array}{l}\text { Neo-liberalism (Post-Fordism } \\
\text { Society) }\end{array}$ \\
\hline Lost Essence Of Life & Liberation Movements \\
\hline Loss Of Spiritual Meanings & Psychological awarness \\
\hline Neglected social Values & Social Justice \\
\hline Neglected Human Rights & Social Democracy \\
\hline Political former authorities & Social institutions and parties \\
\hline Maximizing The Performativity & $\begin{array}{l}\text { Performativity with quality of the } \\
\text { process }\end{array}$ \\
\hline Standardization ideology & Individualism ideology \\
\hline Seeks Organization & Seeks Freedom \\
\hline Industrial based economy & Commodity based economy \\
\hline $\begin{array}{l}\text { Communities main domains are } \\
\text { political and economic powers }\end{array}$ & $\begin{array}{l}\text { Communities' main domains are } \\
\text { political, economic \& social power. }\end{array}$ \\
\hline
\end{tabular}

Table 1: The Revolutionary changes from Fordims to Post-Fordism Societies

Meanwhile, revolutionary changes were basically in the socio-cultural context, architecture witnessed a revolutionary pattern of practice which generated a new morphological theme with its own visual characteristics influenced by these social transformations. This is considered a new addition to the architecture language across the history of practice to shift in patterns like shown in (Figure:4):

\footnotetext{
${ }^{1}$ K. M. Atikur Rahman, 'Globalization and Cultural Transformation: The Case of Bangladesh', Asian Culture and History, 6.2 (2014), 1-10 <https://doi.org/10.5539/ach.v6n2p1>.

2 Andria K. Wisler, “"Of, by, and for Are Not Merely Prepositions”: Teaching and Learning Conflict Resolution for a Democratic, Global Citizenry', Intercultural Education, 20.2 (2009), 127-33 <https://doi.org/10.1080/14675980902922143>.

${ }^{3}$ Thomas A Dutton, 'After Modernism : What Happened to Architecture 's Social Project ?', 1995, 22231.
} 


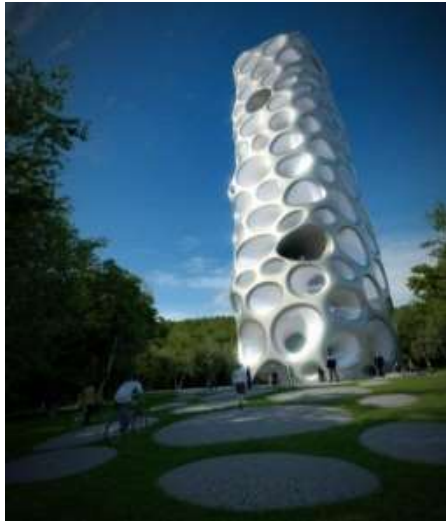

(a) Organic forms

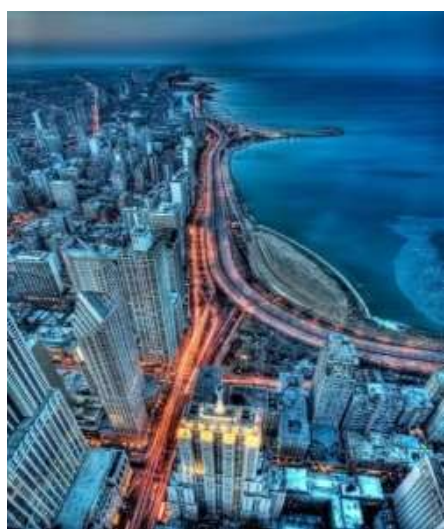

(d) Various lots orientations

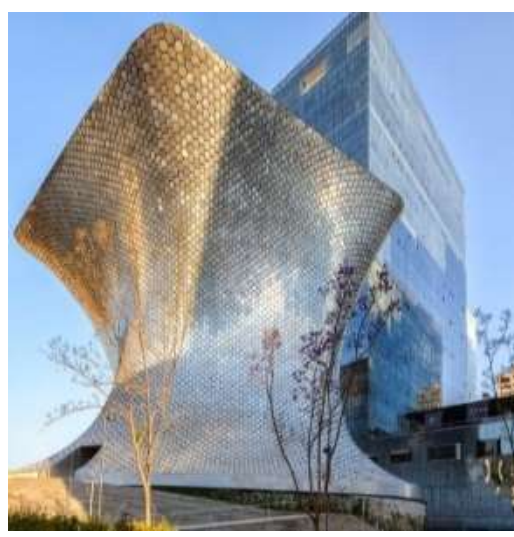

(b) Free form construction

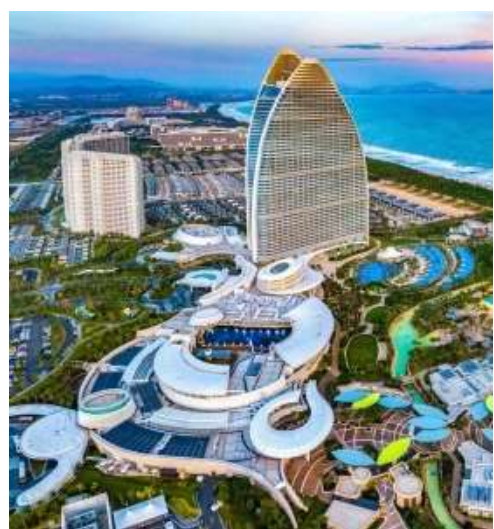

(e ) Different

skylines

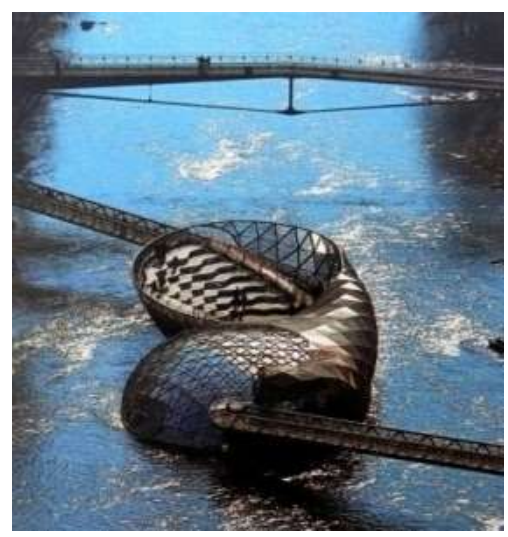

(c) Building in water

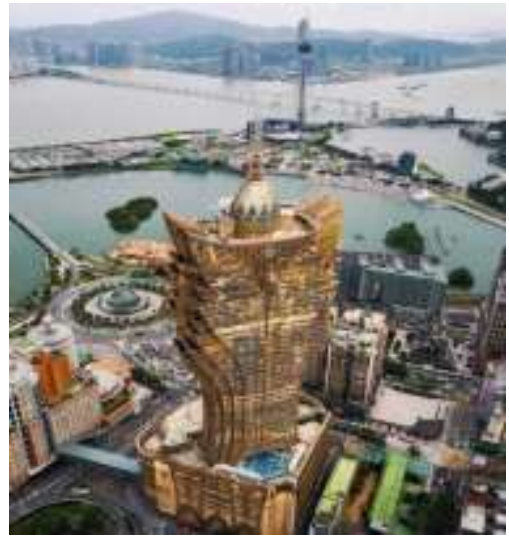

(f) Adhering

buildings styles

Figure 4: The revolutionary architectural themes in post-fordism society

\section{Analyzing Paradigmatic Transitions Across The History of Architecture}

More interpretations to the theory of evolutionary and revolutionary changes across architectural paradigms will be obtained by studying examples to these transitions:

\subsection{The Paradigm Transition from Renaissance to Modern Architecture}

The architectural movements are consistent with the developing universal concepts and technologies, like after the the industrial revolution in 1830 and the transformation from hand work to industrial production ${ }^{1}$, the Renaissance paradigm was rejected and replaced by the Modernity paradigm (Table:2), A new slogan 
demonstrated "Ornament is a crime!". Le Corbusier announced "a feather on a woman's head is sometimes pretty, though not always, and never anything more".

\begin{tabular}{|c|c|}
\hline Renaissance Architecture & Modern Architecture \\
\hline \multicolumn{2}{|l|}{ Influences } \\
\hline $\begin{array}{l}\text { Extension of Roman empire and influenced } \\
\text { by Byzantinein 12th century. }\end{array}$ & $\begin{array}{l}\text { Influenced by the industrial revolution and } \\
\text { mechanized age in } 20^{\text {th }} \text { century.. }\end{array}$ \\
\hline \multicolumn{2}{|l|}{ New Functions } \\
\hline $\begin{array}{l}\text { - Roman basilica as a model } \\
\text { for the new churches. } \\
\text { - Schools attached to certain monasteries } \\
\text { similar to the universities. }\end{array}$ & $\begin{array}{l}\text { - Railway stations. } \\
\text { - Department stores. } \\
\text { - Exhibition halls. } \\
\text { - Bridges. }\end{array}$ \\
\hline \multicolumn{2}{|l|}{ Theme } \\
\hline $\begin{array}{l}\text { Picturesqueness, Sober and dignified } \\
\text { obtained by the grouping of the towers, and } \\
\text { the projection of the transepts and choir. }\end{array}$ & $\begin{array}{l}\text { A return to the basic elements and simple } \\
\text { form compositions that is very functional } \\
\text { and discarding the usage of any ornaments. }\end{array}$ \\
\hline \multicolumn{2}{|l|}{ Materials } \\
\hline $\begin{array}{l}\text {-Local Stones } \\
\text {-Coarsely walls } \\
\text {-Granite } \\
\text {-Flint }\end{array}$ & $\begin{array}{l}\text { - Brick walls } \\
\text {-Steel } \\
\text {-Concrete } \\
\text {-Glass }\end{array}$ \\
\hline \multicolumn{2}{|l|}{ Featured elements } \\
\hline $\begin{array}{l}\text {-The plain cross vaulting } \\
\text {-Exterior buttresses } \\
\text {-Semicircular arches } \\
\text { - Receding rectangular opening planes. } \\
\text {-Placed circular columns }\end{array}$ & $\begin{array}{l}\text {-A free glass façade; non-supporting walls } \\
\text {-Open floor plan } \\
\text {-Roof garden } \\
\text {-Exposed rigid structural system } \\
\text {-Free-standing wall and partitions. }\end{array}$ \\
\hline 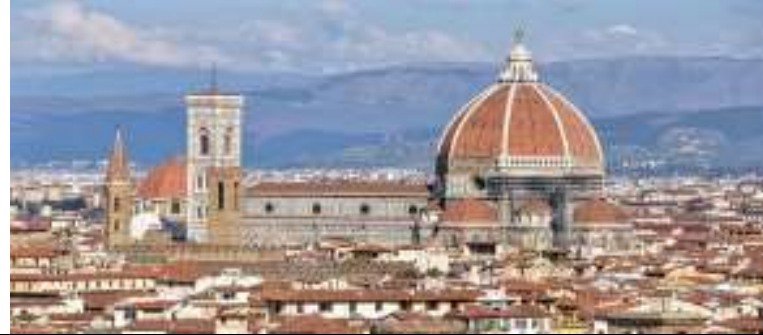 & 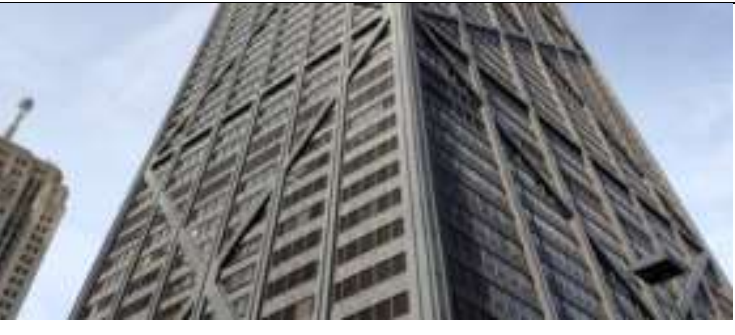 \\
\hline Filippo Brunelleschi, Santo Spirito, Florence & $\begin{array}{l}\text { John Hancock Center, Skidmore,owings } \\
\text { \&Miller. }\end{array}$ \\
\hline
\end{tabular}

Table 2: Architectural paradigm substitution model from Renaissance to Modern Architecture

(1) Sigfried Giedion, “Le Corbusier in Genf”, Neue Zürcher Zeitung no.1403, 27 July 1932, p.27 


\subsection{The Paradigm Transition From Hi-Tech to $4^{\text {th }}$ Generation Architecture}

Hi-Tech developed by the $1960 \mathrm{~s}^{1}$, is defined as "An Architectural style that rejects traditional methods and aims to develop construction techniques beyond time without forming any associations with past styles"2. known for its structural expressionism, mechanized theme, functional priorities, and the economic leadership of modernity. The technology of industrialization and the innovative materials produced were the heart of the movement, the power of the new structural systems, building materials and the used building systems were higher than any aesthetical sense of the building. The the pioneers of Hi-Tech were Richard Rogers and Renzo Piano with their early influential Pompidou Centre in France 1977 (Figure:5-a).

However, with the high demands of energy saving solutions and attentions to the eco-system, Hi-Tech Architecture shifted to Organi-Tech Architecture. The sharp straight edges of the buildings transferred to smooth and curved ones owes to the new technologies that reduced the cost of of the new compositions. Mixing unfamiliar shapes and counter-movement positions were dominant on buildings. Buildings were built relative to their strong-form, with no priority to wind directions, ventilations or orientations, From the pioneers: Nicholas Grimshaw.and Santiago Caltrava who designed the city of arts and sciences in Valencia1998(Figure:5-b).

Later on, Piano began to show some commitments to the ecological system in his design of The International Airport Terminal of Japan, he tried to merge between architecture and nature offering some passive techniques, planting programs and introducing slightly environmental solutions to achieve the so called "Hi-Tech Utopia" (Figure:5-c). The new shapes required the computer participation in design and construction that introduced the approach "Craftsmanship by computer" 3 . By the end of $20^{\text {th }}$ century, Piano lead the movement to serious concerns to the environment and the eco-system on his scheme for Tokyo Tower Building (Figure:5-d). Transitioning from Hi-Tech architecture to the latter developed HI-Tech Adaptive Architecture, pointing the future to serve the environment through building design, Norman Foster was one of the pioneers with Swiss-re Tower design in London(Figure:5-e).

\footnotetext{
${ }^{1}$ Charles Jencks, The Architecture of the Jumping Universe: A Polemic: How Complexity Science Is Changing Architecture and Culture, Academy Edit, 1997.P.109

2 Asena Soyluk, Zeynep Yeşim İlerisoy, and Ezgi Dadaş, 'Evaluation of High-Tech Architectural Movement From 20Th Century To Today in Terms of Construction Materials and Structure', March, 2020, 172-84.P.173

${ }^{3}$ Ibid, P.115
} 
In beginning of the $21^{\text {st }}$ century, the Adaptive-Performance based design with the reflections of the high evolutions of technology in all life disciplines, new approaches, processes, BIM and intelligent control systems served the contemporary concerns of nature, environment and resources. New terminologies appeared in architecture which are: "Adaptive-Interactive-Responsive-Performative and lately the $4^{\text {th }}$ Generation Architecture", (Figure:5-f). Maybe we can call this "The New Complexity Paradigm". The Pioneers who inspire this movement are: SOMA, Herzug and de Meuron, Patrik Schumacher and BIG architects. This movement is currently one of the most recognized practice that serve the philosophy of the age by different means, it makes use of the latest technologies, properties of materials, softwares, and management systems to erect and stimulate the behavior of the building to optimize its consumption and add intelligence to its performance detecting variables like occupants behavior, environmental conditions, thermal comfort, and user preferences.

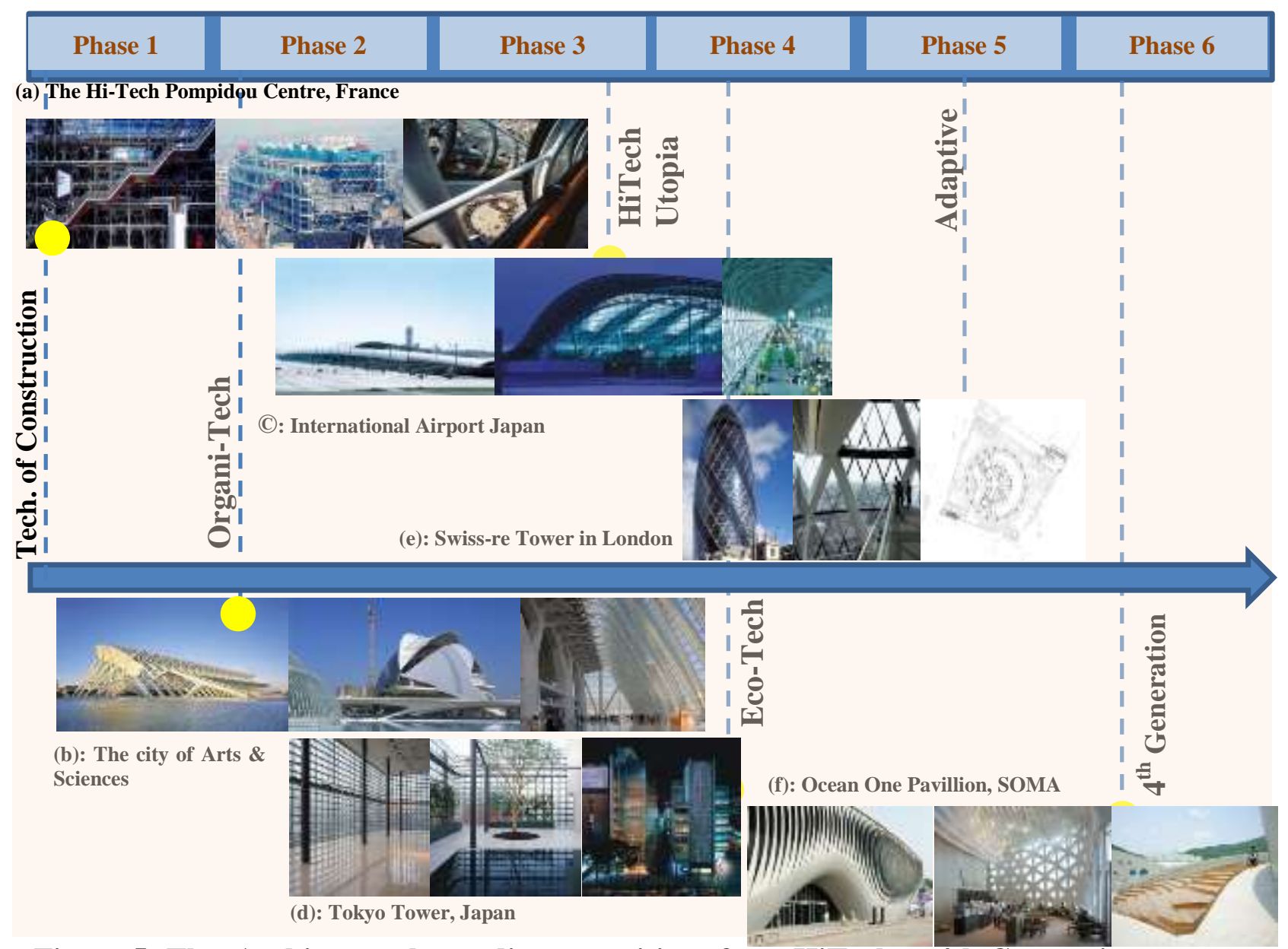

Figure 5: The Architectural paradigm transitions from HiTech to 4th Generation Architecture 


\subsection{The Paradigm Transition From Vernacular Architecture to Sustainability}

Despite no negative criticism has been truly recorded against the paradigm of vernacular architecture, it doesn't appear anymore widely spreading among the architectural community and the iconic projects of the contemporary $21^{\text {st }}$ century. While new terminologies appear to demonstrate the current practices like Glocalization, Green architecture, Ecological architecture, Environmental architecture, and Sustainable architecture, which will be critically discussed as follow:

Vernacular architecture is the basic practice that can be detected since the beginning of life on earth, it is defined as: where the early human began to build with the local allowed materials his basic needs of hut which evolved to hut and temple later forming "The Pre-historic Architecture" as seen in (Figure:6a).Vernacular architecture evolved generating a popular style for each civilization, distinguished by common features and primitive structure systems forming "The Historical Styles" "2 as found in Egypt the House, Tomb and Temple buildings (Figure:6-b).

In the $19^{\text {th }}$ century the term "Vernacular" evolved by the two leading pioneers:

- Hassan Fathy: who introduced in his book: "Architecture for the poor: An Experiment in Rural Rgypt" his philosophy and approach on "Gourna village" project to obtain a cost-effectice "affordable" building prototypes that respects the user, climate, environment and culture (Figure:6-c) added to 2010 Watch, The UNESCO and The World Monumenets Funds ${ }^{3}$.

- Bernard Rudofsky: whose visionary theory in his book "Architecture without Architects" defined several practices within the paradigm of vernacular architecture which "never goes through fashion cycles", like: Skeletal, Celestial, Symbolic vernacular, Castles, Grass structures, and Fujian Tulou as an iconic vernacular example that has been added to the UNESCO as world heritage site in $2008^{5}$ (Figure:6-d) .

Hence, Vernacular architecture seems to be an extended approach that has many folded meanings and principles regarding climate, nature, material, construction and users, but we may recognize transitions through it during the $21^{\text {st }}$ century:

Critical Regionalism is a movement where an identity crisis have been reached, the over abstraction of the industrial model, globalization and the international style

${ }^{1}$ BANISTER FLETCHER, A HISTORY OF ARCHITECTURE ON THE COMPARATIVE METHOD. (BRADBURY, AGNEW, \& CO. L1X, PRINTERS, LONDON AND TONBRIDGE., 1905).P.54

${ }^{2}$ Ibid, P.56

3 'Https://Www.Wmf.Org/Project/New-Gourna-Village'.

${ }^{4}$ Bernard Rudofsky, Architecture without Architects, an Introduction to Nonpedigreed Architecture, The Museum of Modern Art: Distributed by Doubleday, Garden City, N.Y. (The Museum of Modern Art: Distributed by Doubleday, Garden City, N.Y., 1964) <www.moma.org/calendar/exhibitions/3459>.P.11

5 'Https://Whc.Unesco.Org/En/List/1113/'. 
of dominant architecture has led to a situation of belongingness, spacelessness and seeks for the genius locai or the phenomenology of space. The philosophy of this school highlights the question how will we cultivate our civilization for the future if we didn't sustain our existence today?

- Norberg Schulz leaded this movement influenced by the philosophy of Martin Heidgger in his book "Genius Locai-Towards A Phenomenology of Architecture" he defined the strong place as "Considering the skyline of the town and the horizontally expanded silhouette of the urban buildings as keys to the image of a place" .

- Jorn Utzon the Danish architect later introduced the "New Tradition", he called for architecture that is site specific and poetic, emphasizing the concepts of form aesthetics, respecting nature, innovative materials and functionality for social values ${ }^{2}$. This thematic approach was the door to many iconic projects like: Bagsvaerd Church (Figure 7-a)with its pre-cast concrete elements and shell vaults casted in site over the religious space, where the technology of materials is used to produce normative elements that keep the native language of the place besides using the traditional wooden fenestration and slatted partitions. Also opera Sydney in Australia (Figure 7-b)that represents apart from the sculpture identity of the place. Utzon approach was named "Additive Architecture"3 that refers to architecture grows in site from nature.

- Oscar Niemeyer regionalism philosophy was greatly influenced by the organic inflections, linking the place identity strongly with the influence of nature. In tension with the modernism approach of rising the building on columns he called for bringing the house back on earth, linking with the planned landscape, water features and the surrounding nature like his Canoas House Design (Figure 7-c).

In the $21^{\text {st }}$ century superior terminologies like efficiency, regionalism, local materials and sustainablility has been dominating the philosophy of architects and practitioners, more attention has been given to the resources, rates of consumptions, human well-being and the impact of built environment on nature. Despite the major difference can be recognized in the value-belief system between vernacular and critical regionalism, the larger paradigm of sustainable architecture holds the previous subordinate ones with wider vision and more specified boundaries that serve the goals of vernacular and critical regionalism through a more mature generalized approach.

\footnotetext{
1 Norberg Schulz, Genius Loci, Semiotica, 2000, CXXVIII <https://doi.org/10.1515/semi.2000.128.34.233>.

${ }^{2}$ Adrian Carter, 'Between Earth and Sky: The Work of Jørn Utzon, as an Exemplary Phenomenological Approach to Modern Architecture Made Concrete', Architecture and Phenomenology, 2009, 1-14 <https://vbn.aau.dk/ws/portalfiles/portal/18037260/Kyoto-paper.pdf>.P.2

${ }^{3}$ Ibid.
} 
Subsequently, approaches of sustainable design are leading architecture in the current era, the most influencing approaches are detected as follow ${ }^{1}$ :

1. The Respect for the Wisdom of Natural systems - the Bio-mimicry principle

2. The Respect for People -The Human vitality principle

3. The Respect for Place - The ecosystem principle

4. Respect for the Cycle of Life - The "Seven Generations" Principle

5. Respect for Energy and Natural Resources - The Conservation Principle

6. Respect for Process - The Holistic Thinking Principle

It is remarkable that most of the buildings appreciated and rewarded within the contemporary practices are sustainably oriented with respect to the three pillars of sustainability: People, Planet and Profit. We may retrieve examples in (Figure:8).

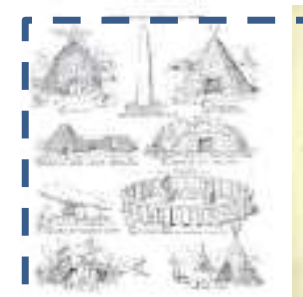

(a)Prehistoric Vern. Arch

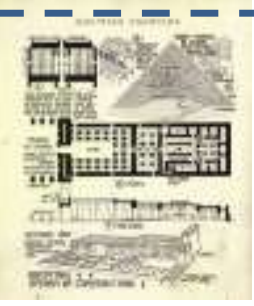

ᄂ - - - - - -

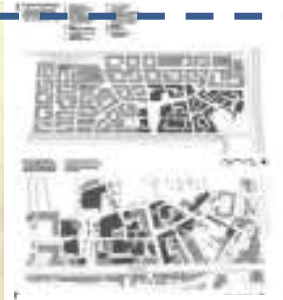

(b)Gourna Village, Luxor

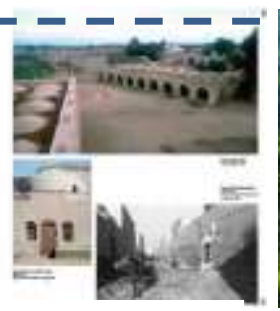

(c)Fujian Tulou, China

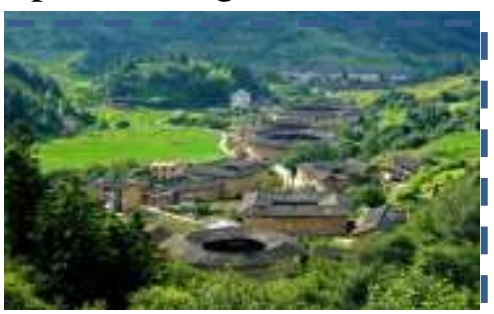

I

Figure 6: The Paradigm of Vernacular

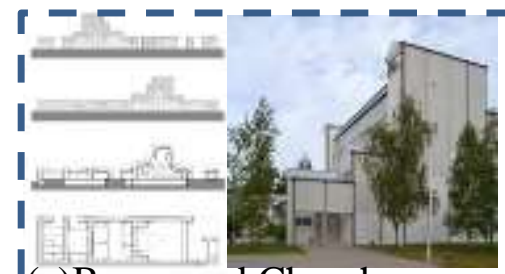

(a)Bagsveard Church,

Australia

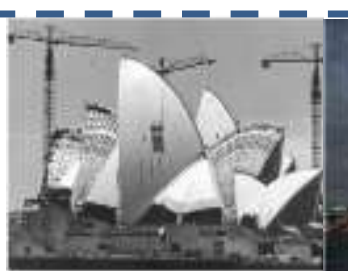

(b)Opera Sydney, Australia

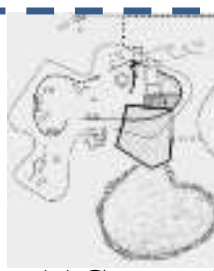

(c)Canoas House Design, Brazil

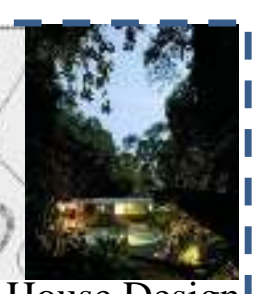

I

Figure 7: The Paradigm of Critical Regionalism Architecture

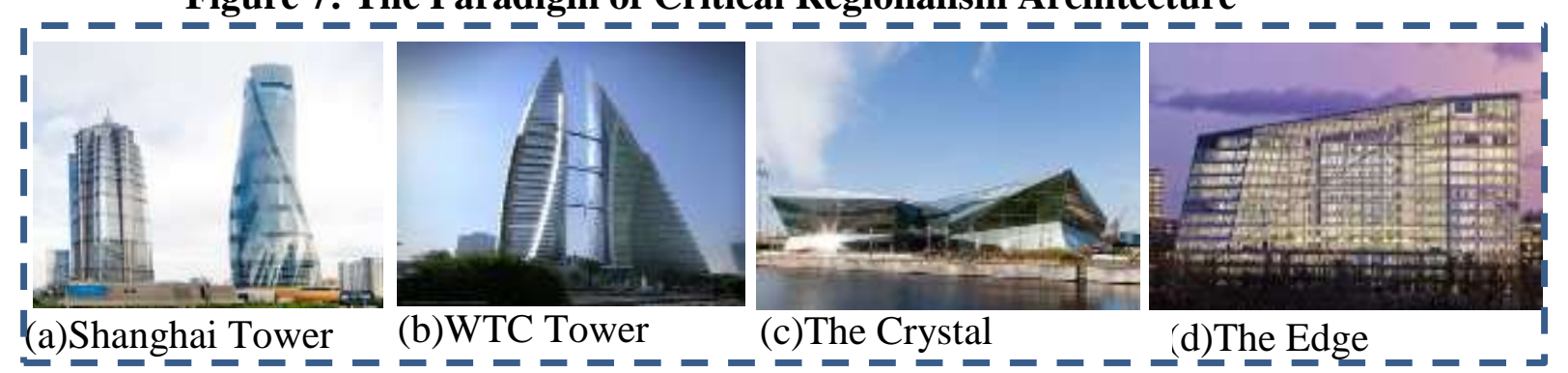

Figure 8: The Paradigm of Sustainable Architecture

\footnotetext{
${ }^{1}$ Ayman A.Farid, 'Art of Sustainable Design in Architecture - A Critical Analysis for Sustainable Design Development Paradigm', 2016, 195.P.61
} 


\section{Results and Discussions}

Through recognizing the changes and transitions of the previously discussed architectural paradigms, some results can be extracted and summarized in this section.

\subsection{Drivers of change of Architectural Paradigms from practice to theory}

By recognizing the changes and transitions of the previously discussed architectural paradigms it is concluded that in the first paradigmatic transition from Renaissance to Modernism the driver of change was the belief of the new adapted knowledge accompanied the industrial revolution with the rise of the mechanical age and the conceptions of pure functionality and the power of machine. This revolutionary change in the paradigm of the age shifted all the values and the philosophies of beauty, art and aesthetical values to a new horizon of functionality and abstraction. New realities were built accordingly and new design approaches evolved creating new morphology of buildings that is drastically differs from before, resulting in the glass facades, free corners, partitions, skyscrapers and elevated buildings.

While the second paradigmatic transition from Hi-Tech architecture to the perfromative or smart or as called $4^{\text {th }}$ generation architecture shared a common belief of an idea of the power of technology and its impact on architecture that enabled its practitioners to follow and adapt the new knowledge of advanced technologies across ages till today to add parameters of adaptations and performativity of buildings as smart-idioms that serves the initial-basic belief. The drivers of changes here are both the belief of the building smart-capabilities and the adapted knowledge of information technologies that engage IOT, Machine Learning and automated responses.

Finally, the third studied paradigmatic transition from vernacular to critical regionalism to the superior sustainability paradigm rests on the evolution of their basic belief of an idea concerning the essence of place and its resiliency to adopt an extended cloud of minor beliefs,ideas, values and meanings that all interrelate to serve this basic belief and reaches a richer platform that embraces all these multiple values. Accordingly, the driver of change here is only the belief which informs and inspires the evolution of the architectural practice towards a comprehensive mature paradigm.

Based on the previous discussion the drivers of paradigm change in architecture are concluded as shown in table 3: 


\begin{tabular}{|l|l|l|l|}
\hline Changes & $\begin{array}{l}\text { From Renaissance to } \\
\text { Modernism Paradigm }\end{array}$ & Driver & Knowledge \\
\hline Second Case-study & $\begin{array}{l}\text { Krom Hi-Tech to 4 } \\
\text { generation Architectural } \\
\text { Paradigm }\end{array}$ & Driver & Knowledge and Belief \\
\hline Changes & $\begin{array}{l}\text { Frand } \\
\text { Third Case-study }\end{array}$ & Belief \\
\hline Changes & $\begin{array}{l}\text { From Vernacular and } \\
\text { Critical Regionalism to } \\
\text { The Sustainability } \\
\text { Architectural Paradigm }\end{array}$ & Driver & \\
\hline
\end{tabular}

Table 3: Comparative analysis between the different transitions across the architectural paradigms

This comparative analysis leads us to extract the fact that drivers of change of architectural paradigms work through two models (Figure:9): either a coherent merge between knowledge and Idea, or incoherent drivers of : adopted knowledge or an idea.
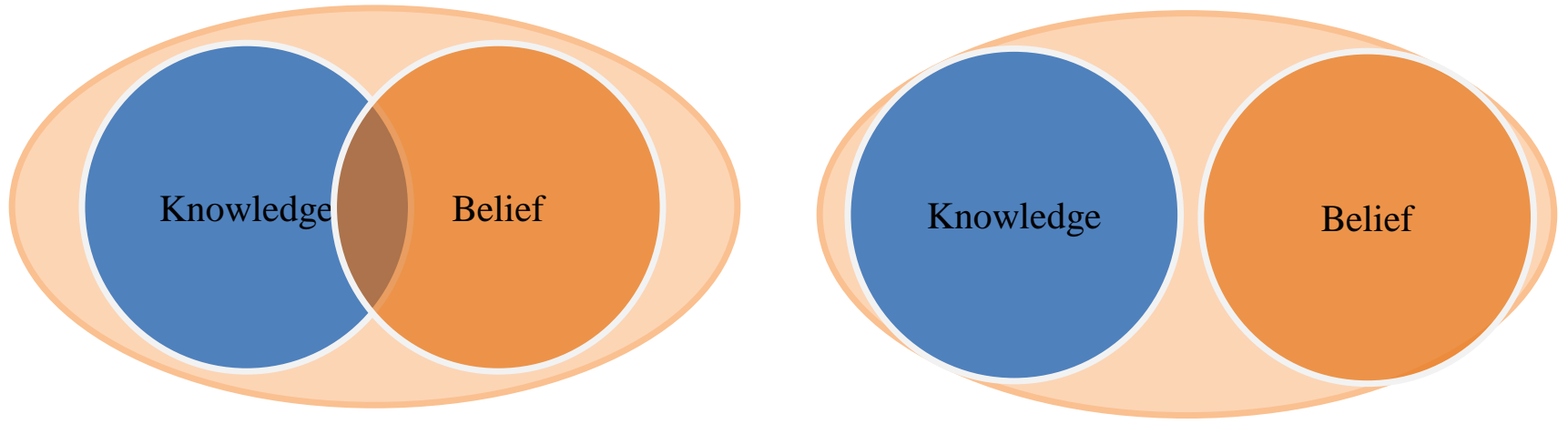

Figure 9: The different models of the drivers of changes of architectural paradigms

\subsection{A New Perception to The Possible Interrelations Between different co-existing architectural paradigms}

Meanwhile the hill-climbing paradigm identifies two types of changes in the paradigms of innovations; the evolutionary changes within the same paradigm aiming to reach the peak, and the revolutionary changes that leapfrog from the traditional paradigm towards a new paradigm of innovation representing a paradigm shift. The critical analysis of the different transitions and changes of architectural paradigms reveals three types of possible paradigm shift from one paradigm to another rather than the only introduced prototype which will be discussed below: 
- The substitution changes: that express the transitioning from one paradigm to another with complete refutation to the other. As each paradigm has its own fundamentals of Epistemology, ontology and methodology, and they should be isolated for alternative views without any attempts for reconciliation or hegemony in the intellectualism of each paradigm, where the paradigms here considered competing and not complementary at all.

- The blossom changes: : that express the transitioning from one paradigm to another with the same beliefs but more mature values and potentials. As the aim of all attempts is to get a more developed structured practice seeking perfectionism "as long as the diversity can be resolved at some point" ", which takes us back to Kuhn's concern about possible communication between the paradigms. This integration promotes seeking similarities of terminologies and give probabilities of the outcomes of paradigms if considered either "new concepts" or "evolutions".

- The supremacy changes: : that express the transitioning from more than one paradigm to another with the multiple richer beliefs, more mature values and potentials. This advocates the supremacy of a dominant paradigm "meta level paradigm", that embraces subordinates aiming to achieve richer knowledge. Exploring the difference in the foundational components of each paradigm, that we may accept parts of the truth of each paradigm to get a better collective understanding of the current version of reality".
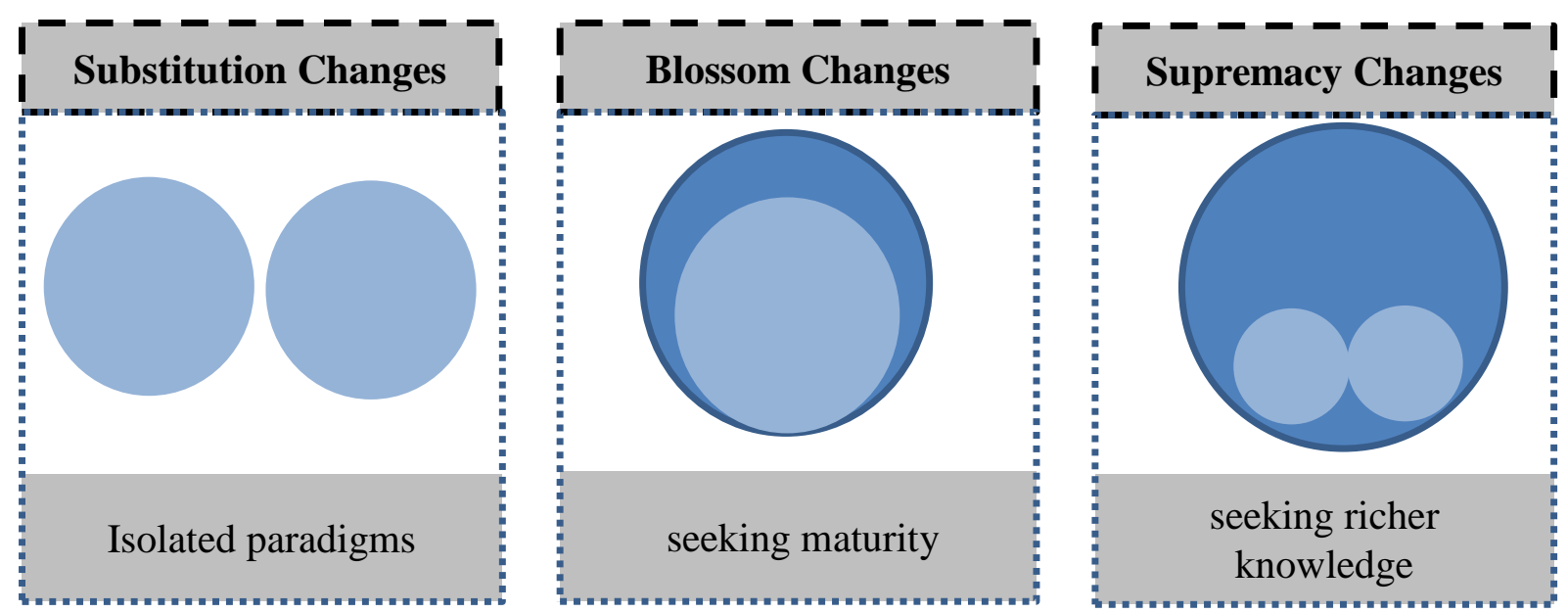

Figure 10: The Possible Interrelations Between different co-existing architectural paradigms

\section{Conclusions}

\footnotetext{
1 Jeffrey Pfeffer, 'Barriers to the Advance of Organizational Science: Paradigm Development as a Dependent Variable', The Academy of Management Review, $18.4 \quad$ (1993), 599 <https://doi.org/10.2307/258592>.
} 
The philosophy of paradigm shift in architecture is identified through the critical understanding of the progress and transitions of paradigms. By exploring the nature of scientific paradigms and the hill climbing paradigm models, these transitions were found primitively classified to evolutionary changes that tends to perfectionism within the same paradigm and revolutionary changes with drastic shift from one paradigm to another due to changes in meanings or new technologies.

Through the analysis of the different paradigmatic transitions of architecture across history, a new theory rises to identify the drivers of paradigm changes "The knowledge-belief system"; the knowledge stands for facts and science innovations as seen in the era of the industrial revolution, while the belief stands for the controlling idea or religious as mentioned by Kuhn ${ }^{1}$, this is seen in the paradigm of sustainable architecture as well as the preceding Gothic architecture. These drivers are found to be the elementary motors of paradigmatic-changes. Clearly, they have two models of performance either coherently: knowledge and belief, or incoherently: knowledge or belief as concluded from the discussed case-studies.

Furthermore, the discussion extracted three types of transitions from one architectural paradigm to another rather than the primitive revolutionary change in hill-climbing model, these three transitions give critical articulation to the architectural paradigms in the $21^{\text {st }}$ century, where a crisis is known to exist after the failure of the modernism cultural paradigm and a fragmentation of knowledge and practices is recognized among the architectural community. These transitions are summarized as :

1. The Substitution changes from one paradigm to another, characterized by being completely isolated.

2. The Blossom changes from one paradigm to more developed one, sharing the same basic belief and values but with higher capabilities and mature identity.

3. The Supremacy changes from multiple subordinate paradigms to a parent paradigm with collective knowledge of beliefs, values and intentions towards a richer platform of architectural practices.

\section{REFRENECS}

Ayman A.Farid, 'Art of Sustainable Design in Architecture - A Critical Analysis for Sustainable Design Development Paradigm', 2016, 195

Van der Berge, 'Dialectics and Functionalism: Toward a Theoretical Synthesis', American Sociological Review, 28.5 (1963), 695-705

BERMUDEZ, J, 'On Paradigms \& Avant Garde: Peeking into the Architectural Mind', Design Methods, 30.3 (1996), 1-19

<http://www.arch.utah.edu/people/faculty/julio/parad.htm>

\footnotetext{
${ }^{1}$ Kuhn.
} 
Carter, Adrian, 'Between Earth and Sky: The Work of Jørn Utzon, as an Exemplary Phenomenological Approach to Modern Architecture Made Concrete', Architecture and Phenomenology, 2009, 1-14

<https://vbn.aau.dk/ws/portalfiles/portal/18037260/Kyoto-paper.pdf>

Charles Jencks, "The Architecture of Jumping Universe ”, Academy Edition, Great Briton, 1997

Dutton, Thomas A, 'After Modernism : What Happened to Architecture' s Social Project ?', 1995, 222-31

FLETCHER, BANISTER, A HISTORY OF ARCHITECTURE ON THE COMPARATIVE METHOD. (BRADBURY, AGNEW, \& CO. L1X, PRINTERS, LONDON AND TONBRIDGE., 1905)

Hassard, John, Sociology and Organization Theory,Positivism, Paradigms and Postmodernity, עלון הנוטע (Cambridge University Press, 1993), LXVI

'Https://Dictionary.Cambridge.Org/Dictionary/English/Paradigm'

'Https://Whc.Unesco.Org/En/List/1113/'

'Https://Www.Merriam-Webster.Com/Dictionary/Paradigm'

'Https://Www.Wmf.Org/Project/New-Gourna-Village'

Jencks, Charles, The Architecture of the Jumping Universe: A Polemic: How

Complexity Science Is Changing Architecture and Culture, Academy Edit, 1997

Kaminer, Tahl, Architecture, Crisis and Resuscitation: The Reproduction of PostFordism in Late- Twentieth-Century Architecture, Architecture, Crisis and Resuscitation: The Reproduction of Post-Fordism in Late-Twentieth-Century Architecture, 2011 <https://doi.org/10.4324/9780203831847>

Kuhn, Thomas S., The Structure of Scientific Revolutions, The Structure of Scientific Revolutions (University of Chicago Press, 1970) <https://doi.org/10.7208/chicago/9780226458106.001.0001>

Metcalf, Stephen, 'Neoliberalism: The Idea That Swallowed the World', The Guardian, 2017

Norman, Donald A., and Roberto Verganti, 'Incremental and Radical Innovation: Design Research vs. Technology and Meaning Change', Design Issues, 30.1 (2014), 79-85 <https://doi.org/10.1162/DESI_a_00250>

Peck, Jamie, Nik Theodore, and Neil Brenner, 'Neoliberal Urbanism Redux?', International Journal of Urban and Regional Research, 37.3 (2013)

<https://doi.org/10.1111/1468-2427.12066>

Pfeffer, Jeffrey, 'Barriers to the Advance of Organizational Science: Paradigm Development as a Dependent Variable', The Academy of Management Review, 18.4 (1993), 599 <https://doi.org/10.2307/258592>

Rahman, K. M. Atikur, 'Globalization and Cultural Transformation: The Case of Bangladesh', Asian Culture and History, 6.2 (2014), 1-10 <https://doi.org/10.5539/ach.v6n2p1>

Rudofsky, Bernard, Architecture without Architects, an Introduction to 
Nonpedigreed Architecture, The Museum of Modern Art: Distributed by Doubleday, Garden City, N.Y. (The Museum of Modern Art: Distributed by Doubleday, Garden City, N.Y., 1964) <www.moma.org/calendar/exhibitions/3459>

S, Thomas Kuhn, 'Review Articles', 1971, 287-97

Schulz, Norberg, Genius Loci, Semiotica, 2000, CXXVIII <https://doi.org/10.1515/semi.2000.128.3-4.233>

Soyluk, Asena, Zeynep Yeşim İlerisoy, and Ezgi Dadaş, 'Evaluation of High-Tech Architectural Movement From 20Th Century To Today in Terms of Construction Materials and Structure', March, 2020, 172-84

SUN, Ya-Guang, 'Wind-Bracing Systems and the Materials of Chicago School (Architecture) at the End of 19th Century', DEStech Transactions on Engineering and Technology Research, mdm, 2017 <https://doi.org/10.12783/dtetr/mdm2016/4939>

Williams, Dorothy Giles, and Earl R. Babbie, 'The Practice of Social Research.', Contemporary Sociology, 5.2 (1976), 163 <https://doi.org/10.2307/2062956>

Wisler, Andria K., "“Of, by, and for Are Not Merely Prepositions": Teaching and Learning Conflict Resolution for a Democratic, Global Citizenry', Intercultural Education, 20.2 (2009), 127-33 <https://doi.org/10.1080/14675980902922143> 